\title{
An Analysis of Cultural Synergy of China Foreign Aid Program Participants
}

\author{
Yan Li* \\ International Business School \\ Yunnan University of Finance and Economics \\ Kunming, China \\ cyliyan2002@163.com \\ Jin Zhang \\ International Business School \\ Yunnan University of Finance and Economics
}

\author{
Kunming, China \\ ibsyufe_zhang@163.com
}

\author{
Diop Khalifa Ababacar SY \\ International Business School \\ Yunnan University of Finance and Economics \\ Kunming, China \\ khalifasydiop@live.fr
}

\begin{abstract}
This paper mainly addresses the cross-cultural conflict within the organization, measures the cultural state of foreign education aid programs. Based on the "Denison Organizational Culture Model", the investigation team conducted sampling survey. With students in the foreign aid program of Yunnan University of Finance and Economics as the samples, we conducted measurement of the organizational culture of foreign-aid educational program, and analyzed the existence state of cross-cultural conflict. Then proposes corresponding intercultural synergy strategy.
\end{abstract}

Keywords - intercultural synergy strategy; foreign education aid programs; conflict management

\section{INTRODUCTION}

Today, complicated and profound changes are happening to the world, the deep influences of international crisis have been continuously showing. In 2013, China propose "one Belt one Road" initiative, which attracted high attention from the international community. One of the core contents of the policy, interconnection and interworking not only emphasizes policy communication between countries, but also the traffic connection, smooth trade, currency circulation and non-governmental exchanges. Based on that, aid programs focuses on how to carry out the role of big country to help surrounding and neighbor countries promote their people's livelihood programs. The aid is mainly provided to the fields that could directly benefit the citizens in surrounding aided countries, such as poverty alleviation, disaster reduction, vocational education and agricultural development countries.

Since its establishment, this program has successively recruited and trained 2678 students from developing countries. During the implementation of specific foreign-aid educational program, because the students came from many different countries with complicated cultural background, and there are also other realistic problem such as low level of cross-cultural management by the implementing party, it has resulted in different program management and frequent implementing cross-cultural conflicts. If this problem is not

properly addressed, it will generate certain influence on the foreign-aid program.

This paper mainly addresses the cross-cultural conflict within the education aid programs, measures the cultural state and proposes corresponding intercultural synergy strategy.

\section{LITERATURE REVIEW}

\section{A. Theories on Cultural Measurement}

The coexistence of different cultures increases the complexity of management. Cultural differences often lead to different organizational structure, management methods and management effects. How to coordinate the cultural universality and difference of different regions and countries is the main goal of the project. To improve the effectiveness of cross-cultural management, we must first solve the problem of cultural measurement. In cross-cultural studies, many scholars of social anthropology, theoretical basis and methodology and tools of natural science put forward different cultural analysis mode, the mode analysis of the different basic cultural variables or factors, and on the basis of comparative analysis. Such as Holland scholar Hofstede (1990) [1] put forward the multi dimension culture model clear (MMOC); American professor Chatman (1997) [2] of the University of California from the fit way of organizational fit and individual outcome variables, constructed the OCP scale values of the organization. Taiwan scholar from the most basic attribute of enterprise culture with the Taiwan enterprise as the research object, summarizes the characteristics of the oriental culture values of enterprise scale etc. The modern organization theory to act or cooperative behavior as an organization or organized nature, as long as there is no widely cooperation among members of the organization behavior, there is also no organization

\footnotetext{
*Corresponding author
} 


\section{B. Theories on Cultural Synergy}

Cultural Synergy has gradually become the focus of attention in psychology, management and Sociology. This concept was first proposed by Canadian scholar Adler (1986) [3], American scholars Harris and Moran (1996) [4] believed that cultural synergy refers to cultural differences, which can promote the joint development and perfection of all participants in cross-cultural communication, this kind of difference contributes far more to cross-cultural communication than to a single cultural group. German psychologist Alexander Thomas (1996) [5] believes that intercultural synergy refers to "important elements of different cultures (such as adaptation model, values, rules and behavior) in some way together, the sum of these elements to produce a high quality value structure, individual value of the sum is greater than the value of an individual element. The modern organization theory" to act or cooperative behavior as an organization or organized nature, as long as there is no widely cooperation among members of the organization behavior, there is also no organization. For foreign education aid projects, this theory has practical guiding significance. Factors such as communication barriers between managers and members, lead to conflicts in the operation of various projects. Using this theory to guide our cross-cultural conflict management can effectively improve the efficiency of cross-cultural conflict management.

\section{METHODOLOGY}

"Denison culture assessment model" is one of the most effective and practical model to measure the organizational culture status. The paper Based on the "Denison cultural assessment model" combine with the actual situation of foreign aid projects helped designs the questionnaire used in this survey. The questionnaire mainly adopts the combination of closed and opens hand way of the design. The first 60 were closed questions and were used to investigate the understanding of students about organizational mission, team work, sense of participation, communication, communication attitude, internal harmony degree, innovation consciousness, attitude and satisfaction in order to evaluate the status of organizational culture. The last 5 were open questions and were used to identify student learning method, learning style, communication style, student level of understanding of organization spirit, crosscultural organization construction attitude and suggestions, and also detail that closed questions model couldn't cover. Participation and adaptability focus on Organizational Resilience and flexibility. Mission and coherence reflect the organization's ability to maintain predictability and stability. Adaptability and mission are related to the ability of the organization to be adaptable to the external environment, while participation and consistency emphasize the internal culture of the organization. Each question is used to reflect the understanding or attitudes of the investigated person to some aspect of the organizational culture.

The test was conducted by the long-term participants of the foreign aid program of the Ministry of Commerce of Yunnan University of Finance and Economics, a total of 43 questionnaires were distributed and 43 valid questionnaires were collected.

\section{DATA ANALYSIS}

The investigators analyzed the scores on 12 dimensions of Denison Model. Based on the Denison Model, we conducted statistic computation of recovered questionnaires, and the results are as shown in Fig.1.

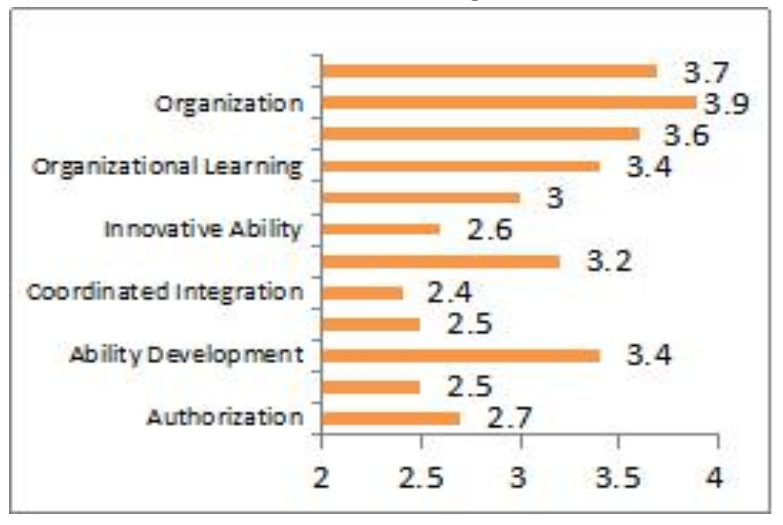

Fig. 1. Culture measurement of Yunnan University of Finance and Economics Foreign Education aid programs

In accordance with Fig.1, we can see that the sores of 12 indices of organizational culture are all controlled around 3 , which reflects that this program has a short operation time, and there is still huge space for improvement on the aspects of organizational culture construction and students' recognition of cultural identity. Among the 12 indices, the organization goal has the highest score, which indicates the students have clear learning goal in the program; the scores of organizational learning, ability development and vision are relatively high, which indicates that the students are clear of the future ideal state and goal of organization, they understand the organizational development direction, and they are satisfied with the management on the aspect of knowledge learning and skill improvement; the score on the dimension of "strategic direction" is high, which reflects fast speed of organizational development, the students have personally experienced the organizational development and reform, and they hold a positive attitude toward the development of organization and macro national environment.

Fig. 1 also shows that this organization has low scores on the dimensions of innovative ability, coordinated integration, commitment and authorization. Among them, coordinated integration has the lowest score, which indicates that the students hold a suspicious attitude toward the organization's management efficiency and ability in solving problems, and the organization still has many aspects to improve on the aspect of cross-cultural management. In the foreign aid project of education, cross-cultural conflicts are manifested at all levels, mainly between the management and the foreign students, Students internal strife, conflicts between students and other social institutions or individuals in China. 
Of course, these cross-cultural conflicts are both constructive and destructive.

The following will focuses on the existing state of intercultural conflict within the organization:

\section{A. Conflict of value culture}

Different cultures and values will lead to different management practices including evaluation, rewards and punishments, interpersonal relationships, etc. For example, in the management mechanism of treating projects, students hope to have more autonomy, and the managers have the right to suggest and challenge, on the contrary, managers often make their own treatment according to the conventions of they own cultural background. In different ways of expression, students from different backgrounds often ask questions straightforwardly, while Chinese people are tactful in their expressions and like to talk behind the scenes. Language barrier is perhaps the first and foremost challenge face by foreign students (studying in China) but this challenge is not literally limited to spoken word, there are also differences in the Chinese way of management as compare to different countries. At the inception of study here in China students experience great difficulties in expressing ideas to the administration.

\section{B. Differences in management methods}

Through the questionnaire survey, the author finds that the satisfaction of foreign students in aid projects is mainly concentrated in the differences in culture or approach of management, which can account for about $45 \%$ of all conflicts. They argue that conflicts between management and management mechanisms are the most common in aid projects. For example, in Europe, the school has complete written materials of the students program, giving information from the entrance to the program to their graduation, which is the entire process. On the contrary, the traditional management of the Chinese people is based on the rule of man (relation between the people). Many problems are random process variation, randomness, system construction, program construction is always in continuity, poor management; inconstant in policy, most of the time notice given by the manager make students confused. Of course, these phenomena are related to our culture. Chinese treatment of problems are more flexible, but when it cross foreign students that like or use to planning in advance, this flexibility is greatly reduced, to the internal cultural construction projects and integration problems.

\section{Difference on institutional culture}

At present, the laws and regulations on foreign students in China are very different from those of other countries and countries where they live. For example international students are not allowed to work in China. For many students from developing countries, life can be very difficult. Urging for they living expenses become one of the main content of their communication with the managers. Not only have those, many students are willing to work voluntarily to gain working experience which will help them to be competitive in the job market at the end of their study program.

\section{Differences in cultural identity}

In the education of foreign aid projects, students mostly from Asia and other regions of the developing countries, because of religious beliefs, values, information channels are limited, Some students still hold a skeptical attitude towards Chinese culture, and conclude that all the problems in life and study come down to the mistakes of Chinese culture. For example some students are sensitive to some sounds because they come from war-torn countries. When the manager announced: "the Chinese New Year has arrived we can have fireworks and firecrackers to celebrate the New Year with local residents." Actually, some students complained that the sound of setting off firecrackers was terrible, and made him/her think of war. So that the Chinese cultural phenomenon with resistance to emotions. This kind of negative emotions spread very quickly in the organization

\section{INTERCULTURAL SYNERGY STRATEGY}

Traditional path to improve the cross-cultural management include cultural dominance, cultural adaptation, cultural compromise, cultural avoidance, etc., but the foreign assistance project organization members come from different cultural backgrounds which increased the difficulty of management, the multicultural characteristic determines the management of using some special cultural trend path is limited. In the multicultural coexistence environment, the cultural synergy strategy is more realistic and feasibility in practice to achieve cultural synergy to develop a new solution. It not only respects all cultures, but also increases the way to work effectively. According to the three steps of the Adler culture synergy theory, we proposed a basic strategy for collaborative management across cultural projects:

\section{A. Identify cultural conflict}

There is a variety of cultures within the program, and the causes of conflict are also complex. Analyzing cultural differences and correctly diagnosing different types of cultural conflicts are especially important in the management of cultural conflicts. First, it is important to identify and differentiate cultural conflicts to take targeted measures to resolve conflicts, be prepared to develop crosscultural understanding. Only understanding mutually, learning mutually, one will learn to respect each other's culture, strengthen the consciousness of cultural conflict and cultural sensitivity, by using effective communication, to reduce the foreign education assistance project crosscultural conflict.

\section{B. Conduct cross-cultural training}

Cross-cultural training is the most basic and effective way to dealing with cultural conflicts and preventing cultural conflicts. Cross-cultural organization culture education and training should include three aspects: first of all, country should strengthen the training of managers and the organizer, the country has invested a lot of money in the 
field of foreign assistance education, but there is a lack of training for the management targeted. Secondly, the training of students' in the ability of cross-cultural communication, with the same project participants from different countries and regions, complex cultural backgrounds, the communication between each other often led to internal conflicts. At the same time, we should pay attention to the organization and training of project diversity culture team.

\section{The establishment of cultural synergy}

In the cross - cultural organization, we should establish the thought of humanistic management and establish the third cultural management idea with the common values as the principle of multi - party work and cooperation. The members should understand that awareness of each other's language is not enough to help smooth and trouble-free relationship. Conscious effort should be made to understand each other's culture. At the same time can also take advantage of multiculturalism, improve the cohesion of members of the organization, centripetal force. When the conflict occurs, the manager should organize the members to jointly select the combination of different cultures, eliminate the sense of national superiority, respect and understand the different cultures, cooperate and work on an equal footing. In this way, cross-cultural organizations can form collective power and build common values, when the members of the organization for the common goal of the struggle, often ignore the factors leading to conflict or dilute the conflict, to establish new core values.

\section{To build an inclusive organizational culture}

Build a tolerant organizational culture: the organization must confirm the legal status of conflict, build an atmosphere that welcomes conflict, form an environment where people can talk freely, and build a system that encourages conflict resolution. Emphasize common strategic goal and system regulation. With common strategic goal, the two parties in conflict will regain their sense of mission and centripetal force, and realize that the goal cannot be realized based on the resource and strength of any one party: as a result, various parties involved in the conflict might be willing to concede or make sacrifice for the goal, and the conflict can be solved; the system is a bottom line, include the behavior of organization members into the regulated scope of system through practical and feasible system, and it is the most basic strategy to prevent, reduce and solve conflict with regulation rather than people.

\section{CONCLUSIONS}

In conclusion, for any organization, harmony is relative, while conflict is absolute. Cultural conflict accompanies the whole process of cross-cultural management. Cross-cultural management is an effective measure to reduce cultural conflict and establish competitive advantages for the organization. The organization should be able to identify the cultural conflict, grasp and utilize cultural conflict, respect cultural diversity, emphasize cross-cultural communication, and conduct cross-cultural training. Based on exploration with scientific method and practical attitude, it can not only realize cross-cultural harmony, but also achieve a management model that can adapt to the diverse culture within the organization, so that the organization can create and maintain its vitality.

\section{ACKNOWLEDGMENT}

This work was supported by the Education Science of Philosophy and Social Science Foundation of Yunnan Province (Grant No. AC16001).

\section{REFERENCES}

[1] G. Hoforede, B. Neuijen, D.D. Ohayv, and G. Sanders, "Measuring organizational culture and effectiveness," Organization science, 1990, pp. 204-223.

[2] J.A. Chatman, "Matching people and organizations: selection and socialization in public accounting firms," Administrative Science Quarterly, vol. 36, 1997, pp. 459-484.

[3] N.J. Adler, "nternational dimension of organizational behavior. Boston: Kent, 1986, pp. 95-117.

[4] P.R. Harris, and R.T. Moran, "Managing cultural differences: High performance strategies for today's global manager," Houston: Gulf, 1996, pp. 2-4.

[5] D. Krewer, "Cultural standard as medium of self and others reflection. In: A Thomas (Hrsg.), Psychology intercultural trades," Göttingen: Hogrefe, 1996, pp. 147-164.

[6] T. Wan, "conflict management," Tsinghua University press, September 2012, p. 4

[7] J.H. Ma, Korea, and X.C. Hu, "Three typical perspectives of crosscultural synergy research," mental science development, vol. 14, 2006, pp. 757-761.

[8] X. Li, and S.T. Gan, "Research on Cooperative Governance of nonprofit organizations," Journal of Changchun University of Technology, 2014, pp. 29-32 